\title{
The Following Papers Will Be Published in the January issue of Opticheskiu Zhurnal (Journal of Optical Technology), vol. 76, no. 1, 2009
}

PACS numbers: 01.10.Cr

DOI: $10.1134 / \mathrm{S} 0030400 \mathrm{X} 09010214$

The following papers will be published in the January issue of Opticheskiu Zhurnal (Journal of Optical Technology), vol. 76, no. 1, 2009.

Computation, Design, and Manufacture of Optical Systems. Basic Errors in the Coaxiality Control Using an Autoreflection Optoelectronic System (A.G. Anisimov, A.M. Aleev, A.V. Pantyushtin, and A.N. Timofeev); Physical Simulation of the TwoWavelength Measuring Technique in an Autoreflection Optoelectronic System for Displacement Monitoring (K.G. Arakantsev and A.N. Timofeev); Geometric and Optical Properties of an Afocal Two-Mirror System (V.I. Batshev and D.T. Puryaev); Development of an Algorithm and Writing of a Program for Enhancing the Potential of the Method of Image Quality Assessment in Optical Systems (Le Zui Tuan and V.K. Kirillovskiǔ); Design and Study of an Interferometer Based on the Ronchi Scheme and Interferogram Interpretation Software (Le Zui Tuan and V.K. Kirillovskiǐ); Feasibility Study of a Design of a Three-Coordinate Anamorphosing System for Measuring the Angular Spatial Orientation Parameters (A.D. Merson and I.A. Konyakhin); Aberration Structure of a Spot of Confusion in the Image of a Point in an Optical System with Decentered Elements (V.A. Zverev and I.N. Timoshchuk); The
Influence of the Image Refocusing on the Structure of an Axial Beam of Rays (V.A. Zverev and I.N. Timoshchuk).

Iconics: The Science of Images. Iteration Algorithm for Determining the Position of Point Radiator Images (D.V. Zhukov, I.A. Konyakhin, and A.A. Usik); The Use of the Moiré Effect for the Precision Enhancement of Diffraction Methods for Monitoring Geometric Parameters and Spatial Locations of Objects (V.N. Nazarov and A.N. Ivanov).

Optical Materials Science and Technology. Specific Features of the Photosensitivity of Laser Photothermorefractive Nano Glass Ceramics Doped with Rare-Earth Ions (A.I. Ignat'ev, N.V. Nikonorov, V.A. Tsekhomskiŭ, and E.V. Tsygankova); Structure Modification of Chalcogenide Vitrous Semiconductors under the Action of Femtosecond Laser Radiation (M.A. Lesik, A.A. Man'shina, A.A. Shimko, and A.V. Averina).
Compiled by L.V. Enushevskaya

Translated by S. Belov 